\title{
O mito no teatro de grupo ${ }^{1}$
}

Prof. Antonio Carlos Vargas Sant’anna² Ana Luiza Fortes Carvalho ${ }^{3}$

Palavras-Chaves: mito, teatro, artista

Resumo: O artigo aborda a análise dos discurso do diretor do grupo do tempo Roberto Mallet, buscando identificar possíveis relações com a mitologia heróica, traçando também paralelos referente ao teatro de grupo brasileiro sob essa perspectiva.

A busca por uma identidade torna-se cada vez mais uma exigência da era contemporânea, repleta de elementos massificadores mesclados com a valorização de posturas individualizadas. A mitologia heróica surge como um instrumento de análise pertinente aos estudos a respeito dessa construção identitária, especialmente no que concerne ao universo artístico. O presente artigo pretende, partindo da análise da entrevista com Roberto Mallet, diretor do grupo Tempo, estabelecer relações entre a mitologia heróica e a construção da identidade artística inserida no contexto do teatro de grupo.

Para a análise proposta, a utilização do termo mito deve ser compreendida no sentido estabelecido pelos autores integrantes do círculo de Eranos ${ }^{4}$, ou seja, como uma ferramenta importante para a compreensão da sociedade, especialmente referente às questões de identidade, e não no sentido corriqueiro do termo, empregado no contexto de histórias falsas ou duvidosas.

O mito heróico pode ser dividido em mitemas, que constituem pequenas histórias contidas nas narrativas mitólogicas que repetem-se incessantemente, possibilitando o estabelecimento de uma linha analítica. A trajetória do herói é repleta de mitemas

\footnotetext{
${ }^{1}$ MITOLOGIA E IDENTIDADE ARTÍSTICA: UM ESTUDO DA PRESENÇA DE MITEMAS HERÓICOS NOS DISCURSOS DE ARTISTAS E CRÍTICOS

${ }^{2}$ Prof. Dr. Do Departamento de Artes Plásticas e Coordenador do Projeto de Pesquisa.

${ }^{3}$ Bolsista de Iniciação Científica PROBIC-UDESC, aluna do Curso de Artes Plásticas.

${ }^{4}$ Organização interdisciplinar de análise científica e filosófica, com caráter multicultural, cujo objetivo principal consistia em explorar vínculos entre o pensamento oriental e ocidental. Perpassa o discurso do Círculo de Eranos a busca pelo sentido, a hermeneútica simbólica e a conjugação dos opostos.
}

DAPesquisa, Florianópolis, v.2, n.4, p. 311-318, 2007. 
relacionados essencialmente a sua origem, infância, juventude, retorno e morte. (HORN, 2006)

Em termos culturais, o artista possui as mesmas características mitológicas do herói, tornando possível o estabelecimento de relações entre eles. O herói surge nas sociedades a partir do momento em que os homens passam a buscar algo para divinizar e simultanemante identificar-se: "Por um lado, o herói, justamente por se desviar da norma humana, é tido pela humanidade, isto é, pelo aspecto coletivo, como herói e de origem divina. Por outro lado (...) ele é um homem como os outros, é terreno, mortal e coletivo" (NEUMANN, 1968, p.110.). Ainda a respeito do desenvolvimento do culto ao herói, Jung afirma que:

\begin{abstract}
Como indíviduo, o homem é um fenômeno cujo direito a existência cabe contestar sob um ponto de vista biológico, já que biologicamente o individuo só tem sentido como ser coletivo ou como parte integrante da massa. Mas o ponto de vista cultural concede ao homem uma significação que o separa da massa e que no correr dos séculos conduz a formação da personalidade, com a qual se desenvolveu conjuntamente o culto ao herói. (JUNG, 1993, p.08.)
\end{abstract}

De forma semelhante as sociedades cultuam seus artistas. A importância da figura do artista é simbólica. De acordo com este princípio, Eliade (1963) estabele que o mito possui a finalidade primordial de fixar os modelos exemplares de todos os ritos e de todas as ações humanas, conferindo significado e valor à existência. Partindo dessas questões é possível compreender o interesse despertado em torno da figura do artista ao longo dos séculos.

De acordo com Vargas, os mitos e manifestações artísticas representam a necessidade humana de encontrar sentido para a própria existência. A análise hermenéutica dos discursos dos artistas pretende desvendar de que forma estas figuras se tornam culturalmente importantes. Para compreender esse fenômeno é preciso estabelecer reflexões de aspectos sociológicos, estruturalistas e também relacionados a antropologia, psicologia e filosofia, especialmente em sua vertente fenomenológica, que concebe que a linguagem artística nunca chega a cortar suas origens com o pensamento mítico, tornando todo o discurso artistíco, essencialmente um discurso repleto de mitologia.

É preciso compreender que o processo de contrução de identidade artistica ocorre sob dois processos simbólicos:

DAPesquisa, Florianópolis, v.2, n.4, p. 311-318, 2007. 
Um é o processo de identificação ou negação dos indíviduos com a figura simbólica do herói. Outro é a identificação do pretenso artista com as práticas e atitudes reconhecidas como artísticas pelas coletividades de inserção do indivíduo (e de outras coletividades que o artista deseja se inserir) (VARGAS p. 28)

Dessa maneira, é possível comprerender que o mito do artista existe para que o mesmo se torne um personagem heróico, atuando assim como símbolo de transcendência.

O objetivo do herói é promover sempre uma ação que beneficie a sociedade, em um nível físico (guerreiro) ou espiritual (asceta), sendo que o guerreiro usualmente atua para provocar uma modificação concreta e social, enquanto o asceta busca provocar uma reflexão interior, mas sempre em direção ao benefício coletivo. Nesse sentido, a verdadeira obra de arte é considerada aquela em que o artista vivencia a experiência simbólica do seu heroísmo. Estes ideais permeiam também os discursos dos artistas, permitindo a compreensão dos papéis heróicos que são almejados pelos mesmos.

Nesse contexto, o teatro de grupo configura um objeto de estudo desafiador, uma vez que se baseia não em uma identidade individual, mas sim, na construção de uma identidade coletiva permeada pelas diversas personalidades de seus integrantes. Sendo a mitologia do herói primordialmente baseada na análise da figura individual, é pertinente pensar de que forma esta idéia perpassa a questão da construção de uma identidade heróicoartística grupal. Uma alternativa possível é promover a análise contextualizada dos diversos integrantes do grupo de acordo com suas funções ou mesmo do material publicado em nome do grupo, configurando uma criação identitária coletiva, de forma que este discurso se sobrepõe à questão das individualidades.

O teatro de grupo ${ }^{5}$ constitui uma categoria de organização e produção teatral em que um núcleo de atores movidos por um mesmo objetivo e ideal realiza um trabalho em continuidade e, estende sua atuação a outras áreas, à própria concepção do projeto estético e ideológico, criando uma linguagem que o identifica.

A prática teatral coletiva não constitui uma modalidade específica, uma vez que o teatro é uma arte que exige inexoravelmente a pluralidade de relações. Enquanto as artes plásticas, em geral, são solitárias, o teatro além de ser produzido coletivamente, para se concretizar como arte exige a presença de espectadores. A formação de companhias surge,

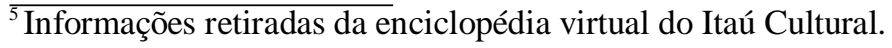

DAPesquisa, Florianópolis, v.2, n.4, p. 311-318, 2007. 
então, como uma estratégia de sobrevivência. Portanto, o 'teatro de grupo', aqui qualificado, não é uma mera organização coletiva, mas sim um contraponto artístico (e mesmo heróico) ao teatro comercial vigente.

A seguir, a análise da entrevista com Roberto Mallet discorrerá sobre duas camadas: uma relacionada à construção mitológica da figura artística do próprio Mallet, e outra que busca perceber como ele se posiciona em relação ao fenômeno cultural do teatro de grupo, fornecendo informações de como concebê-lo mitologicamente.

Roberto Mallet é diretor e ator do grupo Tempo, sediado na cidade de São Paulo e fundado em 1992. De acordo com o endereço virtual do grupo (GRUPO TEMPO, 2007) a principal linha de trabalho desenvolvida tem sido a reflexão teórica e prática sobre teatro, arte e filosofia, tendo a poética da ação teatral como questão central.

Ao longo da entrevista esses ideais ficam claros nas falas do diretor do grupo. A busca por levar esse trabalho reflexivo ao público, fazendo-o questionar-se sobre sua própria existência aparece como uma constante, configurando no discurso a reprodução de uma importante característica heróica: a ação em beneficio da coletividade.

\footnotetext{
Acho o Galpão um grupo coerente. Eles fazem teatro para um público. (...) eu acho que eu faço também. As pessoas não gostam do teu trabalho quando não é popular. Mas não é porque não é popular. É porque você está falando umas coisas que elas não querem ouvir. "Ah, então o problema é seu, mas eu estou falando disso para o seu bem, você vai morrer." (MALLET, 2005, p.63)
}

Ainda nesse pequeno trecho outra característica de Mallet fica evidente: o aspecto contestatório. Este aspecto permeia a entrevista apontando para três importantes mitemas: o do exílio/abandono, o da marginalização social e o domínio das armas relacionado à inteligência, sendo estas características mitológicas observáveis no entrevistado.

O exílio/abandono é representado pelo isolamento do herói e sua conseqüente marginalização social. Este isolamento possui dois aspectos opostos: por um lado fere e por outro protege, pois permite que o herói desenvolva sua prática livre de influências de seu meio social, além de ressaltar sua natureza "única". "Estes mitemas auxiliam os artistas a aceitarem com mais naturalidade as dificuldades (econômicas, de convívio social, políticas, etc.) de sua escolha de vida" (VARGAS, p. 94)

${ }^{6}$ Refere-se ao tema central do espetáculo "Lições de abismo".

DAPesquisa, Florianópolis, v.2, n.4, p. 311-318, 2007. 
Ao comentar a prática de pesquisa no teatro de grupo afirmando ser esta completamente oposta à lógica vigente, Mallet evidencia o mitema citado acima: "É nadar contra a corrente, se você quiser de fato, manter princípios, processar tudo com tempo pra chegar numa obra, você está nadando contra a corrente.” (MALLET, 2005, p. 59).

O mesmo ocorre em sua exposição a respeito da ideologia de que quem ousar discordar do que é unânime é "exilado", mitema que retoma diversas vezes:

Existe uma certa censura, só que essa censura já está internalizada na gente. Não é mais preciso proibir porque ninguém fala mesmo. A própria comunidade se encarrega de coibir qualquer um. Ela simplesmente o expulsa do seu convívio. (...) É uma estrutura de bode expiatório. (...) É você ou fulano que é expulso da comunidade, que é castigado pra que ela seja purificada, etc." (MALLET, 2005, p.52)

A esse respeito é interessante notar também que Tadeusz Kantor ${ }^{7}$ surge como mestre, um modelo a ser seguido, cuja exclusão no meio cultural promove uma espécie de identificação ainda maior no entrevistado: “Como é possível que o Kantor seja tão mal conhecido nesse país? Um cara que revolucionou a cena contemporânea e que fez coisas admiráveis.” (MALLET, 2005, p.58)

Neste contexto o discurso de Mallet evidencia a sua relação com o mitema do domínio das armas, promovendo uma demonstração de habilidade ligada à luta heróica, apontando especificamente para dois aspectos: a inteligência e o humor, expressos por meio de uma atitude constantemente contestatória, como fica evidente na fala a seguir:

Tem outra influência muito forte que vem da França que é a filosofia pósmoderna, o Derrida, o Deleuze, que fizeram uma crítica à história da filosofia. O Foucault. Foucault "neguinho ama". Estes caras, se você tomar, por exemplo, um Deleuze, um Derrida, um Foucault, eles estudaram toda a história da filosofia, e fazem uma crítica a ela, a Platão particularmente, a Aristóteles, a Sócrates, enfim, Hegel, Descartes. Os nossos estudantes, os nossos doutores, inclusive, eles estudaram Derrida, Deleuze. Eles não estudaram Platão, Aristóteles. Você precisa de muitos anos de vida pra estudar estes caras. (MALLET, 2005, p.53)

Em resumo, os aspectos acima citados indicam que a construção mitológica da figura artística do próprio Mallet evidencia-se no sentido da personalidade asceta, que pretende transfigurar habilidades, permitindo que a sabedoria conquistada na jornada

\footnotetext{
${ }^{7}$ Artista plástico polonês, teórico e diretor teatral, fundador (com Maria Jarema) da companhia teatral CRICOT 2 (1995), nasceu em Wielopole, Polônia.
}

DAPesquisa, Florianópolis, v.2, n.4, p. 311-318, 2007. 
heróica seja apresentada à humanidade para transformá-la, espiritualmente ou existencialmente.

A outra vertente desta análise do discurso de Roberto Mallet busca perceber a sua posição sobre o fenômeno cultural do teatro de grupo. As informações coletadas na entrevista identificam a associação do projeto do teatro de grupo com a jornada heróica da ação em benefício do outro, o que se torna claro na afirmação de Mallet: "Se você quer ter prazer fazendo teatro, abandone esta porcaria. Agora se você quer dar prazer pros outros, pro público, aí sim. Teatro é feito pro público.” (MALLET, 2005, p.63)

Nessa direção os apontamentos de Mallet possibilitam identificar algumas relações entre a mitologia artística e o teatro de grupo. Por exemplo, a construção de uma identidade poética coletiva por meio do treinamento, que pode representar a busca pelo aprendizado heróico, é evidenciada na seguinte fala:

A idéia de continuidade e, portanto, de uma construção, vamos dizer assim, de uma identidade poética que depende também da questão do treinamento, que depende da continuidade do trabalho, enfim, acho essa uma característica fundamental (do teatro de grupo). Porque, se você pega o Teatro de Elenco pra gente contrapor ao Teatro de Grupo, você não tem esse espaço (MALLET, 2005, p. 49)

A partir dela é possível estabelecer ainda uma nítida distinção entre o teatro de elenco, e o teatro de grupo, permitindo indicar que este último possui características que o classificam como marginal, que neste caso representa a permissão de um espaço maior para a criação.

Outro objeto interessante de análise mítica no contexto do teatro de grupo é a figura do diretor. A esse respeito Mallet aponta um caminho interessante ao discutir a idéia de processo colaborativo:

Você tem um diretor. Entretanto, o grupo inteiro, incluindo cenógrafo, dramaturgo, etc, cria a própria encenação do espetáculo, então essa figura do diretor não tem uma responsabilidade pela concepção do espetáculo. Quer dizer, pelo menos é esse o discurso. Eu não acredito muito nisso porque quando eu vejo um espetáculo eu vejo que a cara do Tó [Antônio Araújo] ${ }^{8}$. Eu acho que eles têm idéias comuns, eles têm projetos comuns, mas não há dúvida que a mão da encenação é muito forte. (MALLET, 2005, p.49)

Indicando que a identidade coletiva do grupo surge inevitavelmente das motivações individuais, especialmente a partir do diretor, que ora assume a posição de mestre,

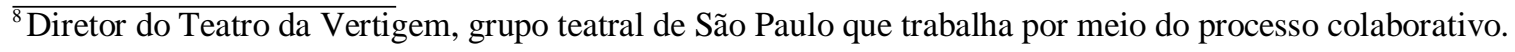

DAPesquisa, Florianópolis, v.2, n.4, p. 311-318, 2007. 
direcionando o trabalho, ora a de mais um elemento no processo de criação dessa identidade.

Estas características apontam para uma manifestação coletiva da jornada heróica, o que poderia ser ratificado por outras análises envolvendo os discursos dos outros artistas do grupo e da trajetória desenvolvida pelo mesmo.

Concluindo, a técnica metodológica que explora o mito do herói no discurso do artista possibilita identificar as associações simbólicas que partem do inconsciente coletivo e se materializam em crenças e práticas que incorporam as características míticas pertencentes às divindades.

A identificação com o mito do herói nas produções artísticas é oportuna para aqueles que, em seu trabalho individual ou em grupo, podem se apropriar deste recurso para evoluírem em suas práticas e mesmo em suas vidas pessoais. O mito nos permite vislumbrar possibilidades e ajuda a compreender melhor papéis e funções quando inserido em um contexto específico. Especialmente a função do artista, que necessita acima de qualquer outra qualidade heróica, promover a sua prática em direção ao benefício coletivo.

De fato, o objetivo heróico de promover uma ação que beneficie a sociedade é um mito que permeia quase todo o comportamento ético das diversas atividades humanas, tanto em seu nível físico (guerreiro) quanto no nível espiritual (asceta). Sendo possível evidenciar a partir da análise da prática artistica a sua essencialidade na compreensão das ações humanas, especialmente no que concerne a busca por um sentido de existência pleno.

\section{Referências Bibliográficas}

ENCICLOPÉDIA DE TEATRO. Disponível em http://www.itaucultural.org.br/aplicexternas/enciclopedia_teatro/index.cfm?fuse action=conceitos_biografia\&cd_verbete=69. Acesso em 10/06/2007, 11:40:33.

GRUPO TEMPO. Disponível em: <http://www.grupotempo.com.br> Acesso em 10/06/2007, 10:30:40. 
HORN, Maria Lucila. Mito de artista: o discurso da cultura. 2006. 122 p. Dissertação. Mestrado em Educação e Cultura-Universidade do Estado de Santa Catarina, Florianópolis, 2006.

JUNG, C.G. Símbolos de transformación. Barcelona: Paidós, 1993.

MALLET, Roberto. Entrevista concedida a Daniel Oliveira da Silva. São Paulo, junho de 2005. Entrevista

MIRCEA, Eliade. Aspectos do mito. Perspectivas do homem. Lisboa: Edições 70, 1963.

NEUMANN, Erich. História da Origem da Consciência. São Paulo: Cultrix, 1968.

VARGAS, Antônio. A Arte do Mito: Considerações sobre a influência da mitologia

artística. (Apostilha de disciplina não publicada) 